\title{
COMPARATIVE STUDY OF RULES EMPLOYED FOR CALCULATION OF PEDIATRIC DRUG DOSAGE
}

\author{
ESTUDO COMPARATIVO DE FÓRMULAS EMPREGADAS NO CÁLCULO \\ DE DOSES MEDICAMENTOSAS INFANTIS
}

Gracieli Prado ELIAS ${ }^{1}$, Cristina ANTONIALI² ${ }^{2}$ Ronaldo Célio MARIANO ${ }^{3}$
1- Graduate student (Master degree), Department of Pediatrics and Social Dentistry of Araçatuba Dental School, São Paulo State University, Araçatuba, São Paulo, Brazil
2- Assistant Professor, Department of Pediatrics and Social Dentistry of Araçatuba Dental School, São Paulo State University, Araçatuba, São Paulo, Brazil
3- Titular Professor, Department of Clinic and Surgery of Universitary Center Federal, Alfenas, Minas Gerais, Brazil

\author{
Corresponding address: Rua Jardim Sumaré, 11 Apto:109 Bairro: Jardim Sumaré, cep: 16.015-270, Araçatuba-SP, Brazil. \\ e-mail: gracieliped@terra.com.br ,fone: (18) 3621-5968
}

Received: May 11, 2004 - Modification: July 28, 2004 - Accepted: October 20, 2004

\begin{abstract}
$T_{\text {he present study was conducted to evaluate the utilization of Clark's, Salisbury and Penna's rules and the Body Surface }}$ Area (BSA) formula for calculation of pediatric drug dosage, as well as their reliability and viability in the clinical use. These rules are frequently cited in the literature, but much controversy still exists with regards to their use. The pediatric drug dosage was calculated by utilization of the aforementioned rules and using the drugs Paracetamol, Dipyrone, Diclofenac Potassium, Nimesulide, Amoxicillin and Erythromycin, widely employed in Pediatric Dentistry. Weight and body surface areas were considered of children with ages between 1 and 12 years old as well as the dosage for the adult. The pediatric dosages achieved were compared to the predetermined dosages in $\mathrm{mg} \mathrm{kg}^{-1}$ herein-named standard dosages. The results were submitted to the parametric test ANOVA and to the Tukey test $(p<0,05)$. The antibiotics and Diclofenac provides acceptable utilization of the rules in pediatric dentistry, however for the Dipyrone, the dosages obtained by the rules suggest their clinical ineffectiveness. For the Paracetamol, the Penna's rule and the BSA formula should not be clinically employed, especially for children between 1 and 5 years old, once such dosages were much close to the hepatotoxic dosage of the drug. It can be concluded that the use of the rules for safe calculation of the pediatric drug dosage is possible and it depends on the used drug and age group. Uniterms: Pediatric dentistry, Oral administration, posology.
\end{abstract}

\section{RESUMO}

O presente estudo foi realizado com a finalidade de avaliar as fórmulas de Clark, Salisbury, Área da Superfície Corpórea (ASC) e Penna, quanto a sua confiabilidade e viabilidade de uso clínico para o cálculo de doses medicamentosas infantis, uma vez que tais fórmulas são freqüentemente citadas na literatura, mas muita controvérsia ainda existe com relação ao seu uso. As doses infantis foram calculadas utilizando as fórmulas descritas e os medicamentos Paracetamol, Dipirona, Diclofenaco de Potássio, Nimesulida, Amoxicilina e Eritromicina, largamente usados na clínica odontopediátrica. Foram considerados parâmetros como o peso e área da superfície corpórea de crianças com idades entre 1 e 12 anos e a dose para o adulto. As doses obtidas foram comparadas às doses em $\mathrm{mg} / \mathrm{kg}$ consideradas como padrão de referência para os medicamentos. Os resultados foram submetidos ao teste paramétrico ANOVA e de Tukey $(\mathrm{P}<0,05)$. Os antibióticos e o Diclofenaco propiciam utilização aceitável das fórmulas na Odontopediatria, porém para a Dipirona, as doses obtidas pelas fórmulas sugerem ineficácia clínica. Para o Paracetamol, o uso clínico das fórmulas de Penna e da ASC para crianças entre 1 a 5 anos é contra-indicado, uma vez que as doses obtidas com tais fórmulas aproximaram-se muito das doses hepatotóxicas do medicamento. Pode-se concluir que o uso das fórmulas para o cálculo seguro de doses infantis é viável, dependendo do medicamento utilizado e da faixa etária.

Unitermos: Odontopediatria; Administração oral de medicamentos, posologia. 


\section{INTRODUCTION}

The most important aspect for selection of a drug and establishment of the proper pediatric dosage is the acknowledgment that the pediatric patient is not just a small adult. Newborns, children and adolescents have different physiological, pharmacokinetic and pharmacodynamic parameters compared to adults. The differences are mainly related to the changes occurring during growth and maturation and require individual dosages. Thus, guidelines of specific dosages and useful means for calculation of pediatric dosages must be developed in order to enhance the effectiveness and therapeutic limit and prevent serious adverse effects ${ }^{19}$.

Two methods are commonly reported as being favorable for definition of the proper pediatric dosage, namely per weight and per Body Surface Area. However, such methods not always yield the same drug dosage, leading to the need of proper evaluation to determine the ideal situation for each individual $^{6}$. Utilization of body weight as a criterion for evaluation of therapeutic dosages should be employed just for mean dosages, usually calculated for antibiotics, since the blood concentrations of the drugs are not proportional to weight $^{10,20}$. Dosages based on the body weight are believed to be insufficient for the achievement of proper serum concentration of most drugs, being the body surface the most valid basis for dosage, since it is related to some physiological functions that account for the differences in pharmacokinetics in patients of different ages ${ }^{2,13,21}$. The effect of drugs is directly related to the blood volume and metabolism, being the Body Surface Area better for calculation of the pediatric dosage ${ }^{7}$. Measurements of the volume of the fluid compartment and investigations on the blood concentrations of drugs have good correlation with the Body Surface Area ${ }^{8}$.

The Salisbury rule also provides dosages within the safe range, close to those recommended by the British National Formulary (BNF), and less prescription mistakes may be expected with its utilization. This rule is closely related to the Body Surface Area, as desirable, and has the further advantage of easier and more reliable calculation ${ }^{8}$. However, Marcondes ${ }^{10}$ suggests better results with utilization of the rule empirically established by Penna, which follows the body surface. It is employed at the Children's Institute (Sao Paulo, SP, Brazil).

The literature review demonstrates that, even though there is a tendency to follow an existing criterion or rule for calculation of the pediatric drug dosage, there are many divergent opinions. MARTIN, et al. ${ }^{11}$ states that the rules employed for calculation of the pediatric drug dosage are not completely satisfactory. Even though many rules for dosage have been developed, it is believed that none has been precise and simple enough for routine use, allowing correct and effective dosage calculation without complicated mathematics ${ }^{8}$. There are several formulas for calculation of the pediatric drug dosage based on weight, age, Body Surface Area or height, yet all of them require careful application ${ }^{14}$. The age from which the rules for pediatric drug dosage may be safely employed is hardly known, and the different rules available for calculation of the pediatric drug dosage may indicate their fallibility ${ }^{18}$. According to Nahata $^{12}$, selection of the most proper rule for calculation of pediatric drug dosages should be careful, since specific pediatric dosages are not available for all drugs. According to the author, investigations on the clinical effectiveness of the dosages achieved should be conducted, even for those rules regarded as the most adequate.

Thus, the present study was performed with a view to evaluate the reliability and possibility of clinical utilization of the existing rules, both by specialists and by dental professionals that occasionally assist children.

\section{MATERIALAND METHODS}

Voluntary children attending the Pediatric Dental Clinic of the Federal University Center of Alfenas (CEUFE) were assessed. Evaluation was conducted in the years 2000 and 2001.

A pilot study was performed for definition of the ideal sample size to allow statistical analysis. Even though 71 children would be enough, the study included 116 children, divided into three groups according to the age range ${ }^{7}$.

* Group 1: 31 children in early childhood, aged 1 to 3 years;

* Group 2: 31 preschool children, aged 3 to 5 years;

* Group 3: 54 school children, aged 6 to 12 years.

$1-1^{\text {st }}$ experimental stage: personal information record of the children and drugs prescribed to the children.

Data were provided by the parents and included personal information of the children such as name, birth date, race, gender and age. Moreover, weight and height of all children were measured by a single examiner on an anthropometric scale (Micheletti, CIMAC, Belo Horizonte, MG- Brazil). Such records were employed for calculation of the Body Surface Area of each child, using a specific nomogram ${ }^{5}$.

The names of the drugs previously employed by the children because of dental treatment were also recorded.

Before interview, the parents signed an informed consent term after being informed on the objectives, benefits and discomforts expected during the study.

The study project was assessed and approved by the Ethics Committee of CEUFE (Protocol \#23087.000691/200212).

$2-2^{\text {nd }}$ experimental stage: utilization of the data for calculation of the pediatric dosages and statistical analysis.

The weight, height, age and Body Surface Area records of the children were employed for calculation of the pediatric drug dosages with utilization of the Clark's ${ }^{13}$, Salisbury ${ }^{8}$ and Penna's ${ }^{10}$ rules and the Body Surface Area (BSA) ${ }^{3}$. Children out of the range of normality (weight/height - age) were excluded from the study. Graphs of weight-height development were considered for evaluation of the normality of children of male and female genders in relation to weight 
and height ${ }^{10}$.

Calculation of the dosages was performed for each child by utilization of the rules mentioned in Table 1 and frequently found in the literature. The pediatric dosages achieved were compared to the predetermined dosages in $\mathrm{mg} \mathrm{kg}^{-1}$, herein named standard dosages, also calculated for each child. The reference drugs employed in the study were those most frequently used in the pediatric clinic: the analgesics Paracetamol (200mg/mL) and Dipyrone (500 mg/mL), the antiinflammatory drugs Diclofenac Potassium $(15 \mathrm{mg} / \mathrm{mL})$ and Nimesulide $(50 \mathrm{mg} / \mathrm{mL})$; and the antibiotics Amoxicillin (250mg/5mL) and Erythromycin (250mg/5mL). The parents during the interview reported these drugs as the most frequently prescribed by pediatric dentists for elimination of pain, inflammation and infectious processes of the oral cavity.

The standard dosages for antibiotics are mentioned in the literature as minimum and maximum (Table 2). Therefore, this was taken into account for comparison between the rules, since the clinically acceptable pediatric dosages should fall within the minimum and maximum values.

All dosages calculated in the present study were pooled and evaluated to verify whether there is a difference in the dosages obtained by utilization of the four rules and the

TABLE 1- Description of the rules employed for calculation of pediatric drug dosage

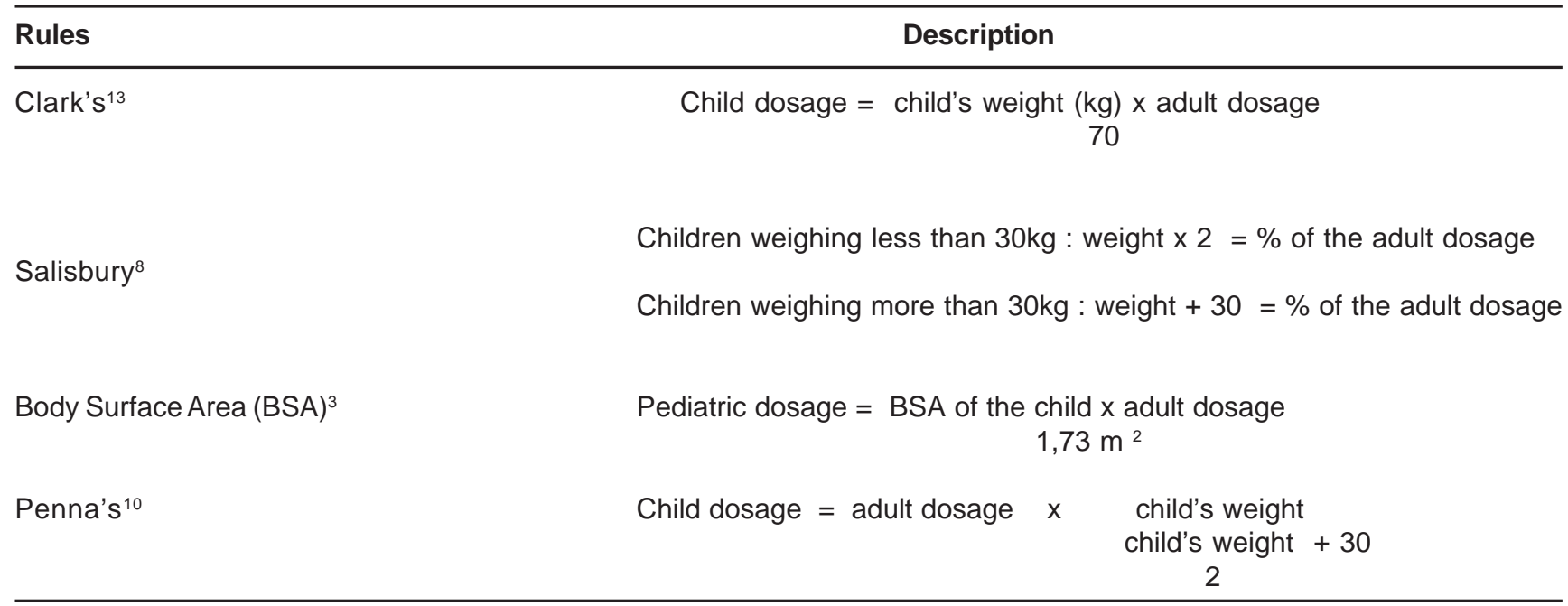

${ }^{*} \mathrm{~m}^{2}=$ square meter

TABLE 2- Main drugs employed in Pediatric Dentistry and their respective dosages for adults and children

\begin{tabular}{lll}
\hline GENERIC NAMES & ADULT DOSAGES STANDARD DOSAGES FOR CHILDREN*
\end{tabular}

PARACETAMOL

DIPYRONE

DICLOFENAC

POTASSIUM

NIMESULIDE

AMOXICILLIN

$500 \mathrm{mg}$ every 8 hours $^{1}$

$500 \mathrm{mg}$ every 4 hours $^{1}$

maximum 5 administrations per day ${ }^{9}$

50mg every 8 hours $^{1}$

100mg every 12 hours

up to $200 \mathrm{mg}$ every 12 hours $^{4}$

ERYTHROMYCIN

$500 \mathrm{mg}$ every 6 hours $^{13}$
1 drop per kg per dosage every 4 or 6 hours maximum 35 drops per dosage and 5 administrations per day ${ }^{4}$

1 drop per kg per dosage every 6 hours $^{3}$

1 drop per kg per dosage Every 8 or 12 hours $^{4}$

1 drop per kg per dosage every 12 hours $^{4}$ $20-50 \mathrm{mg} / \mathrm{kg} /$ day every 8 hours $^{3}$ $30-50 \mathrm{mg} / \mathrm{kg} /$ day every 6 hours / maximum $4 \mathrm{~g} /$ day $^{15}$

* As determined by the manufacturer 
standard dosage $\left(\mathrm{mg} \mathrm{kg}^{-1}\right)$, even for the pediatric patient. Moreover, the statistical significance was calculated, and the possible clinical significance of the differences found was discussed, since the dosages achieved by application of the rules were not clinically tested so far. Determination of the viability of the rules was based on the statistical data.

The data were submitted to the parametric test of analysis of variance (ANOVA) and to the Tukey test at a significance level of $5 \%(P<0.05)$, by means of the Statgraphics Statistical Graphics System software, version 7.0. The mean dosages obtained by the rules were compared for each drug and for each study group, for a better understanding of the outcomes.

\section{RESULTS}

1-Clark's rule

The Clark dosages were not statistically significantly different from the standard dosages $(P>0.05)$ for the drugs Paracetamol, Amoxicillin (20mg/kg/day) and Erythromycin (30mg/kg/day), for the three study groups.

\section{2- Salisbury rule}

In the three study groups and for all drugs employed, the Salisbury dosages displayed statistically significant differences compared to the standard dosages $(P<0.05)$. However, no statistically significant difference was found between the Salisbury and the BSA dosages $(P>0.05)$ for any drug evaluated in Group 3.

\section{3- Body Surface Area (BSA) and Penna’s rule}

Both formulas displayed the same outcomes compared to the standard dosages. For Nimesulide and Erythromycin (50mg/kg/day) in Groups 1 and 2, the BSA and Penna dosages were not statistically significantly different from the standard dosages $(P>0.05)$. All drugs in Group 3 revealed statistically significant differences when the BSA and Penna dosages were compared to the standard dosages $(P<0.05)$.

\section{DISCUSSION}

\section{1- Clark's rule}

From a clinical standpoint, the Dipyrone dosages obtained by the Clark's rule and employed for pain control in the pediatric patient would be much below the therapeutic standard dosage recommended in the 3 study groups (Figure 1). The clinical effect desired may not be achieved with such dosages, yet further investigations with clinical tests should be performed.

As regards to Amoxicillin (50mg/kg/day) and Erythromycin (50mg/kg/day), clinical infection control might be obtained with the Clark dosages, since minimum effective dosages are accepted for these antibiotics (Amoxicillin 20mg/kg/day; and Erythromycin - 30mg/kg/day).

Concerning the anti-inflammatory drugs employed in the present study, incoherent outcomes were found upon comparison of the Clark and standard dosages. Further investigations would be required to check maintenance of the clinical effects with the statistically different Clark dosages for both Nimesulide and Diclofenac. However, it may be observed that the Diclofenac dosages were not above the dosage of $2 \mathrm{mg} \mathrm{kg}^{-1},{ }^{15}$ regarded as the maximum ideal dosage, for Groups 1 and 2; nor were they higher than $50 \mathrm{mg}$, which is the adult dosage recommended, for Group 3.

\section{2- Salisbury rule}

Evaluation of the drugs Paracetamol and Diclofenac in the 3 study groups reveals a statistically significant difference between the values achieved for the Salisbury and standard dosages. However, the Diclofenac dosages were not higher than $2 \mathrm{mg} \mathrm{kg}^{-1}{ }^{15}$, for Groups 1 and 2; nor were they higher than 50mg for Group 3 (Figure 2). Also, the Paracetamol dosages were not higher than the maximum non-hepatotoxic standard dosage accepted for this drug, namely $90 \mathrm{mg} / \mathrm{kg} / \mathrm{day}^{6}$. For more security, additional studies should be conducted to verify maintenance of the clinical effects with the dosages found without the risk of exacerbated or toxic side effects to the pediatric patient.

The behavior of Dipyrone and Nimesulide was similar in all three studies groups. Clinically, the Salisbury dosages for Dipyrone and Nimesulide would be below the therapeutic standard dosage recommended therefore, such dosages might not yield a satisfactory clinical response.

As regards to Amoxicillin (Figure 3) and Erythromycin, a similar behavior was observed for all three studies groups. The Salisbury dosages of these drugs might be employed for infection control in the pediatric patient, since they would be within the therapeutic dosages recommended, i.e. within the minimum and maximum effective standard dosages of

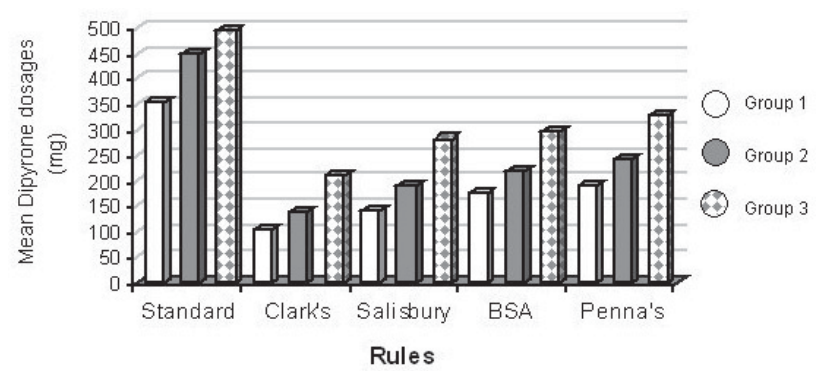

FIGURE 1- Mean Dipyrone dosages for the rules evaluated in the three study groups

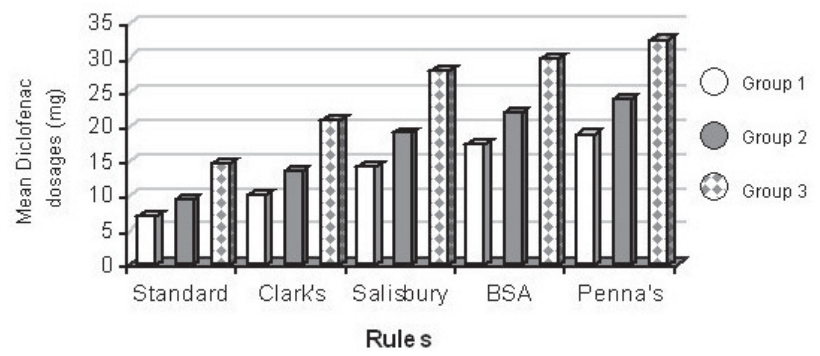

FIGURE 2- Mean Diclofenac dosages for the rules evaluated in the three study groups 
these antibiotics.

According to Lack and Stuart-Taylor ${ }^{8}$, the Salisbury rule allows easy calculations, and ten-year investigations have revealed no clinical evidence of improper dosages. In the authors' opinion, such rule may be employed instead of the BSA in specific situations, since in accordance with Walson, et al. ${ }^{22}$ the body surface may be regarded as a better parameter than weight for determination of drug dosage, even though it comprises measurements that are hard to obtain. Comparison between the Salisbury and the BSA dosages in the present study did not reveal any statistically significant difference for any drug in Group $3(P>0.05)$. The Salisbury dosages calculated in Groups 1 and 2 were always lower than the BSA dosages and presented significant differences for all drugs. These results reveal discordant data compared to those found by Lack and Stuart-Taylor ${ }^{8}$, who demonstrated similar dosages between the Salisbury and BSA dosages and thus indicate utilization of the first because of the easier calculation.

\section{3- Body Surface Area (BSA)}

Paracetamol, Dipyrone, Diclofenac and the antibiotics evaluated presented a similar behavior in three groups. Clinically, the Dipyrone dosages achieved by the BSA formula that would be employed for pain control in the pediatric patient are assumed to be much below the therapeutic standard dosage recommended, not being able to provide proper clinical response. Paracetamol presented BSA dosages much above the therapeutic dosage recommended (Figure 4). Such dosages exceeded or were much close to the hepatotoxic dosage of the drug, especially in groups 1 and 2, upon individual comparison of the children. Verification of the maintenance of the clinical effects with the dosages found without the risk of exacerbated or

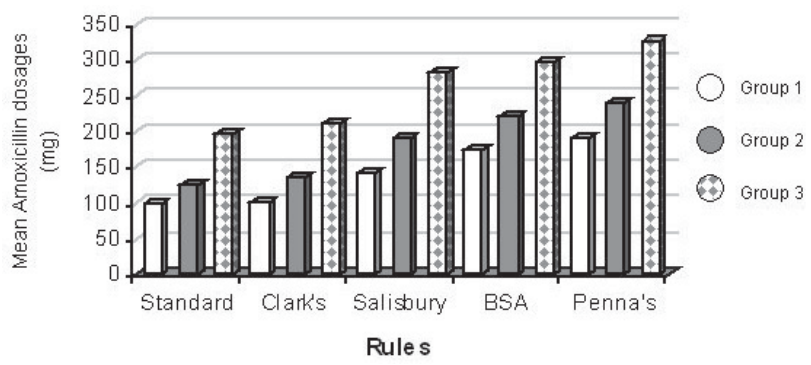

FIGURE 3- Mean Amoxicillin dosages for the rules evaluated in the three study groups

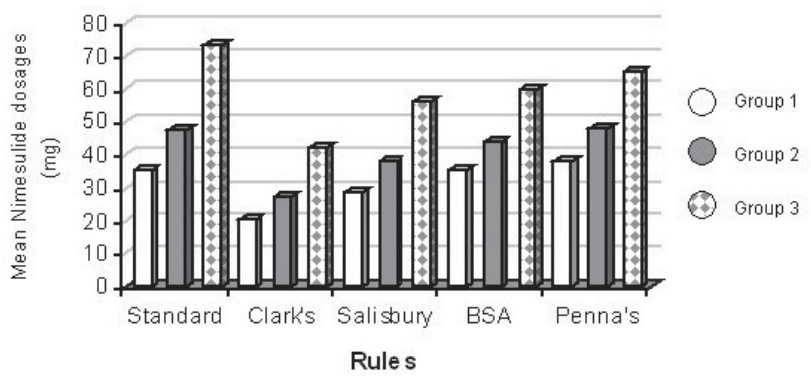

FIGURE 5- Mean Nimesulide dosages for the rules evaluated in the three study groups toxic side effects to the pediatric patient is required. As regards to Diclofenac, the drug dosages obtained by the BSA formula that would be employed for control of inflammation in the pediatric patient are higher than the therapeutic standard dosage recommended and did not exceed the ideal maximum dosage of $2 \mathrm{mg} \mathrm{kg}^{-1},{ }^{15}$, in groups 1 and 2.

Incoherent outcomes were found for Nimesulide (Figure 5). For Amoxicillin and Erythromycin (Figure 6). Despite the statistically significant difference between the standard and BSA dosages, the antibiotic dosages achieved by the BSA formula might be effective for clinical infection control, since they are within the therapeutic dosages recommended.

The results found in the present study for the antibiotics partially confirm the report of Tavares ${ }^{20}$, who stated that the dosages, especially of these drugs, should be calculated on the basis of the child's weight. However, it may be observed that calculation based on the BSA is also acceptable. According to Robinson and Williams ${ }^{16}$, these two methods for dosage calculation are favorable for establishment of the proper pediatric dosage. The authors confirm the outcomes found in the present study, highlighting that both methods not always yield the same drug dosage. However, they present a different opinion on the present results, stating that the differences between the dosages achieved by weight and by the Body Surface Area are larger in younger children. In the opinion of Rodman ${ }^{17}$, the pediatric dosages adjusted by the BSA are substantially higher than the dosages adjusted by body weight, as observed for the drugs Paracetamol and Diclofenac in the three study groups.

\section{4- Penna’s rule}

Results similar to those obtained by utilization of the BSA formula were found by application of the Penna's rule,

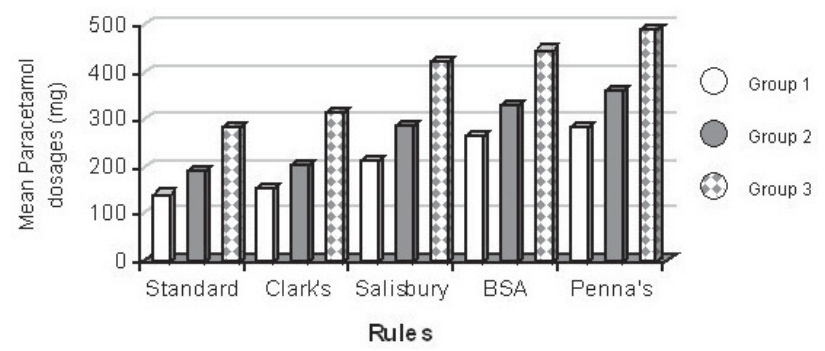

FIGURE 4- Mean Paracetamol dosages for the rules evaluated in the three study groups

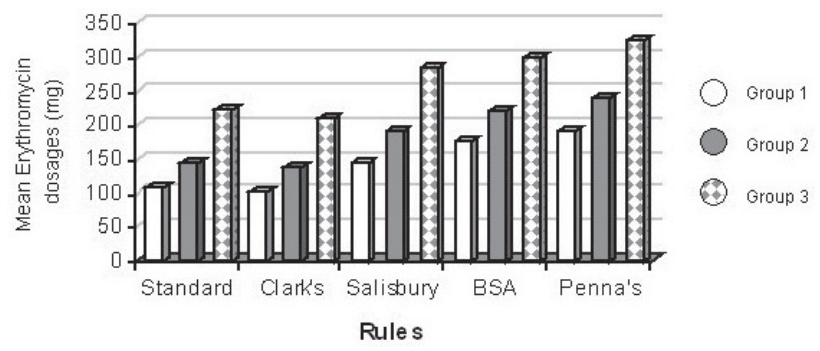

FIGURE 6- Mean Erythromycin dosages for the rules evaluated in the three study groups 
when both were compared to the standard dosage. Such findings corroborate the report of Marcondes ${ }^{10}$, who suggested that the Penna's rule follow the body surface.

The present study demonstrated that the Penna dosages were always higher than the BSA dosages, even though this difference was not statistically significant for some drugs. Nevertheless, the Penna dosages achieved for Paracetamol exceeded or were close to the hepatotoxic dosage of the drug, ${ }^{6}$ especially in Groups 1 and 2 . As regards to Diclofenac and Dipyrone, the results were similar to those achieved by the BSA formula. As to the antibiotics, the Penna dosages were higher than the BSA dosages, yet they were not statistically different from the maximum standard dosages recommended for such drugs.

Despite the higher dosages achieved, the Penna's rule was quite similar to the BSA formula, with the advantage of simpler application.

\section{CONCLUSIONS}

1- Compared to the standard dosage, for the antibiotics evaluated, the Clark's, Salisbury, and Penna's rules and the BSA formula allowed the achievement of dosages above the effective dosage recommended and below the maximum dosage allowed. It provided acceptable utilization in Pediatric Dentistry, since there are few reports of toxicity of these antibiotics.

2- As to Dipyrone, the standard dosages were much above the dosages obtained by the rules, suggesting their clinical ineffectiveness $(P<0.05)$.

3- Concerning Diclofenac, the rules might be satisfactorily applied in the clinics, because the dosages obtained were above the standard dosage $(P<0.05)$, yet they were not higher than the maximum pediatric dosage allowed.

4- In relation to Paracetamol, it is believed that the Penna's rule and the BSA formula should not be clinically employed, especially for children in the age range of Groups 1 and 2.

\section{REFERENCES}

1- Andrade ED. Terapêutica medicamentosa em odontologia: procedimentos clínicos e uso de medicamentos nas principais situações da prática odontológica. São Paulo: Artes Médicas; 2001.

2- Bevan, JA. Fundamentos de farmacologia. São Paulo: Harper and Row; 1981.

3- Corrêa, MSNP. Odontopediatria na primeira infância. São Paulo: Santos; 1998.

4- Def: dicionário de especialidades farmacêuticas. 29th ed. Rio de Janeiro: Epuc; 2000/2001.

5- Departamento científico Racine. Cálculo de fármacos na pediatria. Racine. 1998; 8:26-7.

6- Frank OR; Coulthard KP. Paracetamol for fever in children. Australian Family Phisician. 1996; 17: 771.

7- Guedes-Pinto AC. Odontopediatria. 5th ed. São Paulo: Santos; 1995.
8- Lack JA; Stuart -Taylor ME. Calculation of drug dosage and body surface area of children. Brit J Anaesthesia. 1997;78: 601-5.

9- Lima DC. Manual de farmacologia clínica, terapêutica e toxicologia. Rio de Janeiro: Guanabara Koogan; 1995.

10- Marcondes E. Pediatria básica. 8th ed. São Paulo: Sarvier; 1994.

11- Martin AV, Fernandez PL, Molina JSS, Andres-Trelles F. Farmacologia. 16th ed.

Madrid: Mc Graw-Hill - Interamericana de España; 1993.

12- Nahata MC. Advances in paediatric pharmacotherapy. J Clin Pharm Therap. 1992;17:141-6.

13- Neidle EA. Farmacologia e terapêutica para dentistas. 3th ed. Rio de Janeiro: Guanabara Koogan; 1991.

14- Niederhause VP. Prescribing for children: issues in pediatric pharmacology. Nurse Practitioner. 1997;22:16-30.

15- Nóbrega FJ. Medicamentos habitualmente usados em pediatria. 8th ed. São Paulo: Nestlé; 1997.

16- Robinson GC; Williams VS. Dosage and method of administration of drugs in childhood. Practitioner 1970; 204: 5-13.

17- Rodman JH. Pharmacokinetic variability in the adolescent: implications of body size and organ function for dosage regimen design. J Adolesc Health. 1994;15:654-62.

18- Silva P. Farmacologia. 4th ed. Rio de Janeiro: Guanabara Koogan; 1994.

19- Skaer TL. Dosing considerations in the pediatric patient. Clin Therap. 1991;13:526-44.

20- Tavares W. Manual de antibióticos e quimioterápicos antiinfecciosos. São Paulo:

Atheneu; 1994.

21- Udkow G. Pediatric clinical pharmacology: a practical review. Amer J Dis Child. 1978;132:1025-32.

22- Walson PD, Getschman S, Koren G. Principles of drug prescribing in infants and children: a practical guide. Drugs. 1993;46: 281-8. 